\title{
Comparison of neointimal coverage between everolimus- eluting stents and sirolimus-eluting stents: an optical coherence tomography substudy of the RESET (Randomized Evaluation of Sirolimus-eluting versus Everolimus-eluting stent Trial)
}

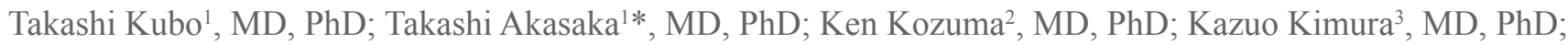
Masaki Kawamura $^{4}$, MD, PhD; Tetsuya Sumiyoshi ${ }^{5}$, MD, PhD; Yasushi Inoํ, MD, PhD; Yoshihiro Morino $^{6}$, MD, PhD; Kengo Tanabe ${ }^{7}, \mathrm{MD}, \mathrm{PhD}$; Kazushige Kadota ${ }^{8}, \mathrm{MD}, \mathrm{PhD}$; Takeshi Kimura9 ${ }^{9} \mathrm{MD}, \mathrm{PhD}$; on behalf of the RESET Investigators

1. Department of Cardiovascular Medicine, Wakayama Medical University, Wakayama, Japan; 2. Division of Cardiology, Teikyo University Hospital, Tokyo, Japan; 3. Division of Cardiology, Yokohama City University Medical Center, Yokohama, Japan; 4. Division of Cardiology, Yokkaichi Social Insurance Hospital, Yokkaichi, Japan; 5. Department of Cardiology, Sakakibara Heart Institute, Tokyo, Japan; 6. Division of Cardiology, Tokai University Hospital, Kanagawa, Japan; 7. Division of Cardiology, Mitsui Memorial Hospital, Tokyo, Japan; 8. Division of Cardiology, Kurashiki Central Hospital, Kurashiki, Japan; 9. Department of Cardiovascular Medicine, Kyoto University Graduate School of Medicine, Kyoto, Japan

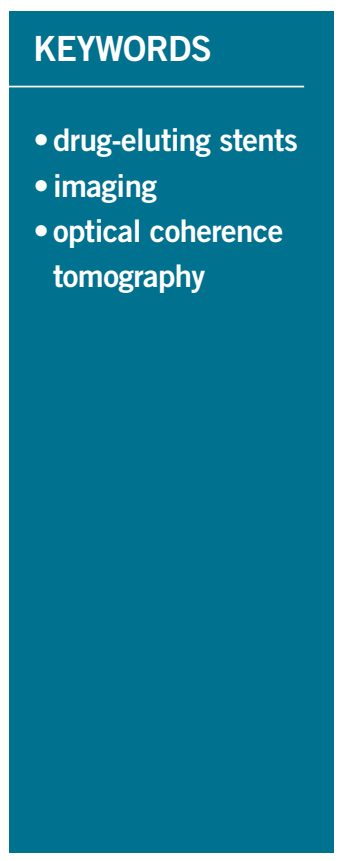

\begin{abstract}
Aims: The aim of the present study was to compare vascular healing response between the first-generation sirolimus-eluting stent (SES) and the second-generation everolimus-eluting stent (EES) by using optical coherence tomography (OCT).
\end{abstract}

Methods and results: The RESET was a prospective, multicentre, randomised, open-label trial comparing EES and SES. Of the 3,197 patients enrolled in the RESET, nine-month follow-up OCT after stent implantation was performed in 100 patients (48 EES-treated lesions in 44 patients and 62 SES-treated lesions in 56 patients), thus constituting the OCT substudy population. The percentage of uncovered struts per lesion $(8 \pm 15 \%$ vs. $14 \pm 19 \%, \mathrm{p}=0.031)$ and cross-sections with $>30 \%$ uncovered struts per lesion $(6 \pm 14 \% \mathrm{vs} .18 \pm 29 \%$, $\mathrm{p}=0.009)$ was significantly lower in EES compared with SES. The frequency of DES-treated lesions with incomplete stent apposition (8 [17\%] vs. 29 [47\%], p<0.001) was significantly lower in EES compared with SES. Intra-stent thrombus was comparably observed between EES and SES (1 [2\%] vs. 5 [8\%], p=0.229).

Conclusions: Compared with SES, EES was associated with a favourable vascular response at nine months after stent implantation.

\footnotetext{
*Corresponding author: Department of Cardiovascular Medicine, Wakayama Medical University, 811-1 Kimiidera, Wakayama, 641-8510, Japan.E-mail: akasat@wakayama-med.ac.jp
} 


\section{Introduction}

First-generation drug-eluting stents (DES) have markedly reduced the incidence of angiographic restenosis and repeat revascularisation in comparison with bare metal stents. However, excessive inhibition of neointimal formation causes delayed healing with incomplete endothelialisation, which may increase the risk of late stent thrombosis ${ }^{1,2}$. Second-generation DES were developed to improve the safety and efficacy of coronary stents by modifying the eluted drugs, drug-carrying systems, and stent designs. The everolimus-eluting stent (EES), a second-generation DES, is a cobaltchromium alloy stent with thin $(81 \mu \mathrm{m})$ strut thickness, which is coated with a thin non-adhesive, durable, biocompatible fluorinated copolymer releasing a reduced dose of everolimus compared with the dose used in the first-generation sirolimus-eluting stent (SES) ${ }^{3}$. Hence, a more favourable vascular healing is expected with EES compared to first-generation DES.

Optical coherence tomography (OCT) is an intravascular imaging modality which employs near-infrared light and provides crosssectional images of tissue with a resolution of $10 \mu \mathrm{m}$. The high resolution of OCT enables in vivo assessment of vascular response after DES implantation, such as neointimal coverage, incomplete stent apposition (ISA), and intracoronary thrombus formation $^{4}$. A recent OCT study showed that patients with very late DES thrombosis had a higher percentage of uncovered and incompletely apposed struts in comparison with control subjects ${ }^{5}$. Therefore, we used OCT to compare vascular healing responses between the firstgeneration SES and the second-generation EES in the Randomized Evaluation of Sirolimus-eluting versus Everolimus-eluting stent Trial (RESET).

\section{Methods \\ STUDY POPULATION}

The RESET was a prospective, multicentre, randomised, openlabel trial comparing an EES (XIENCE $\mathrm{V}^{\circledR}$; Abbott Vascular, Santa Clara, CA, USA) with an SES (CYPHER SELECT ${ }^{\circledR}$ Plus; Cordis, Johnson \& Johnson, Miami Lakes, FL, USA) in terms of target lesion revascularisation. Details of the study protocol have been reported ${ }^{3}$. Of the 3,197 patients enrolled in RESET without any exclusion criteria, nine-month follow-up OCT after the index percutaneous coronary intervention (PCI) procedure (between 8-12 months) was performed in 100 patients, thus constituting the OCT substudy population. The OCT sites ( $\mathrm{n}=16$ centres) were preselected based on their desire to participate in the present substudy. The patients were not randomly selected, but were selected by the OCT site investigators. The exclusion criteria for follow-up OCT were as follows: 1) apparent congestive heart failure, 2) renal insufficiency (serum creatinine $>2.0 \mathrm{mg} / \mathrm{dl}$ ), and 3) lesions unsuitable for OCT imaging (left main coronary artery lesions, ostial right coronary artery lesions, excessively tortuous vessel, and vessel size $>4.0 \mathrm{~mm}$ ). The study was approved by the institutional review board or medical ethics committee at each participating centre, and all patients gave written informed consent. The trial was registered at http://www.clinicaltrials.gov, unique identifier NCT01035450.

\section{CORONARY ANGIOGRAPHY}

Angiograms before the procedure, immediately after the procedure, and at nine-month follow-up were evaluated at a single angiographic core laboratory (Cardiocore, Tokyo, Japan) with the use of CAAS 5.9 (Pie Medical Imaging, Maastricht, The Netherlands). The reference lumen diameter, minimum lumen diameter, percent diameter stenosis ([1-minimum lumen diameter/reference lumen diameter] $\times 100$ ), acute gain (minimum lumen diameter immediately after the index procedure - minimum lumen diameter before the index procedure), and in-stent late lumen loss (minimum lumen diameter immediately after the index procedure - minimum lumen diameter at follow-up) were calculated. In-stent binary restenosis was defined as a diameter stenosis $\geq 50 \%$ at follow-up angiography.

\section{OCT IMAGE ACQUISITION}

OCT examination was performed at nine-month follow-up. A timedomain OCT system (Model M2 Cardiology Imaging System; St. Jude Medical, St. Paul, MN, USA) was used in the present study. Images were acquired as previously reported ${ }^{6}$. In short, a 0.016 inch OCT catheter was advanced to the distal end of the DES-treated lesion through a 3 Fr occlusion balloon catheter. To remove the blood from the field of view, the occlusion balloon was inflated to 0.4 to $0.6 \mathrm{~atm}$ at the proximal site of the DES-treated lesion, and Lactated Ringer's solution was infused into the coronary artery from the distal tip of the occlusion balloon catheter at $0.5 \mathrm{ml} / \mathrm{s}$. For the assessment of the proximal coronary arteries, a continuous flushing (non-occlusive) technique of OCT imaging was used. To flush the vessel, a mixture of commercially available dextran 40 and Lactated Ringer's solution (low-molecular-weight Dextran L Injection; Otsuka Pharmaceutical Factory, Tokushima, Japan) was infused directly from the guiding catheter at a rate of 2.5 to $4.5 \mathrm{ml} / \mathrm{s}$ with an injector pump. Regardless of the OCT imaging technique used, in all cases, the entire DES-treated lesion was imaged with an automatic pullback device travelling at $1 \mathrm{~mm} / \mathrm{s}$. The frame rate of OCT imaging was 15 frames per second. The OCT images were digitally stored and submitted to the core laboratory (Wakayama Medical University, Wakayama, Japan) for offline analysis.

\section{OCT IMAGE ANALYSIS}

OCT image analysis was performed using a dedicated offline review system with semi-automated contour-detection software (St. Jude Medical). All cross-sectional images (frames) were initially screened for quality assessment. Frames were excluded from analysis if any portion of the stent was out-of-the-screen or if the image had poor quality caused by residual blood, sew-up artefact, or reverberation. Qualitative OCT analysis was performed at every frame to detect the presence of intra-stent thrombus. Intra-stent thrombus was identified as a mass protruding beyond the stent strut into the lumen with significant attenuation behind the mass (dimension $\geq 250 \mu \mathrm{m})^{7}$. After calibration adjustment, quantitative OCT analysis was performed at longitudinal intervals of $1 \mathrm{~mm}$ in the DES-treated lesions. Neointimal coverage was assessed on each individual strut. If neointimal coverage of the strut was observed, its thickness was measured from the 
lumen border to the centre of the strut blooming. Intraobserver and interobserver variability for neointimal coverage was assessed in the randomly selected 30 struts and showed excellent concordance ( $\kappa=0.94$ and $\kappa=0.88$, respectively). Also, there was a good correlation for the repeated measurements by the same observer $(\mathrm{r}=0.994)$ and by two different observers $(\mathrm{r}=0.991)$. The proportion of frames with $>30 \%$ uncovered struts was calculated in each DES-treated lesion. The maximum length of segment with uncovered struts was estimated as the number of consecutive frames with uncovered struts. An incompletely apposed strut was defined as a strut with a distance between the centre of the strut blooming and the adjacent lumen border $\geq 110 \mu \mathrm{m}$ in EES and $\geq 180 \mu \mathrm{m}$ in SES. This criterion was determined by adding the actual strut thickness and polymer thickness to the OCT resolution limit (EES: $81 \mu \mathrm{m}+7.8 \mu \mathrm{m}+20 \mu \mathrm{m}=108.8 \mu \mathrm{m}$; and SES: $140 \mu \mathrm{m}+14 \mu \mathrm{m}+20 \mu \mathrm{m}=174 \mu \mathrm{m})$. The maximum length of segment with ISA was estimated as the number of consecutive frames with incompletely apposed struts. Each stent strut condition was classified into one of six categories ${ }^{8}$ : 1) well-apposed to the vessel wall with neointimal coverage on the strut, 2) well-apposed to the vessel wall without neointimal coverage, 3 ) incompletely apposed to the vessel wall with neointimal coverage, 4) incompletely apposed to the vessel wall without neointimal coverage, 5) orifice branch site with neointima, 6) orifice branch site without neointima. Cross-sectional areas of stent, lumen (defined as intra-stent lumen plus extra-stent lumen), neointima (defined as stent minus intra-stent lumen), and ISA (defined as extra-stent lumen) were also measured at longitudinal intervals of $1 \mathrm{~mm}$; volumes were calculated using Simpson's rule. Percent neointima volume obstruction was calculated as neointima volume divided by stent volume. At the maximum neointima area site, neointimal tissue characteristics were assessed and classified into one of three categories: 1) homogenous, 2) heterogeneous, and 3) layered. Homogenous neointima was characterised by uniform optical properties without focal variations in backscattering pattern, heterogeneous neointima by focally changing optical properties with various backscattering pattern, and layered neointima by concentric layers with different optical properties (an adluminal high scattering layer and an abluminal low scattering layer $)^{9}$.

\section{STATISTICAL ANALYSIS}

Categorical variables were presented as frequencies, with comparison using chi-square statistics or Fisher's exact test (if there was an expected cell value $<5$ ). Continuous variables were presented as mean \pm standard deviation and were compared using an unpaired Student's t-test. No correction for clustering at strut level was performed. A p-value $<0.05$ was considered statistically significant.

\section{Results}

\section{PATIENT CHARACTERISTICS}

The present study consisted of 48 EES-treated lesions (59 stents) in 44 patients, and 62 SES-treated lesions ( 75 stents) in 56 patients. Baseline clinical characteristics, including coronary risk factors and clinical presentations at the time of index procedure, were similar between the patients with EES and SES (Table 1). The mean follow-up time was $9.5 \pm 1.5$ months in patients with EES and $9.5 \pm 2.1$ months in patients with SES ( $\mathrm{p}=0.858)$. Aspirin and thienopyridines were continued throughout follow-up for all patients.

\section{ANGIOGRAPHIC FINDINGS}

Angiographic findings and procedural characteristics are shown in Table 2. Quantitative angiographic measurements before index procedures, stent profiles, and procedural characteristics were similar between EES and SES. Minimum lumen diameter after stenting was comparable between EES and SES $(2.60 \pm 0.52 \mathrm{~mm}$ and $2.59 \pm 0.42 \mathrm{~mm}$, $\mathrm{p}=0.964)$. At follow-up, there were no significant differences in instent minimum lumen diameter $(2.44 \pm 0.55 \mathrm{~mm}$ and $2.38 \pm 0.55 \mathrm{~mm}$, $\mathrm{p}=0.585)$, percent diameter stenosis $(14 \pm 14 \%$ and $17 \pm 14 \%, \mathrm{p}=0.325)$, and late lumen loss $(0.14 \pm 0.47 \mathrm{~mm}$ and $0.22 \pm 0.35 \mathrm{~mm}, \mathrm{p}=0.399)$ between EES and SES. In-stent binary restenosis appeared in three $(6 \%)$ EES-treated lesions and three (5\%) SES-treated lesions $(p=0.999)$, which received target lesion revascularisation. There was no stent thrombosis during the follow-up period.

\section{OCT FINDINGS}

There were no OCT procedure-related complications. A total of 1,148 frames with 10,712 struts in EES and 1,408 frames with 11,860 struts in SES were analysed. Of all recorded frames, $4 \%$

Table 1. Patient characteristics.

\begin{tabular}{|c|c|c|c|}
\hline & EES & SES & $p$-value \\
\hline Number of patients & 44 & 56 & \\
\hline Age, years & $68 \pm 9$ & $68 \pm 9$ & 0.894 \\
\hline Gender, male & $35(80)$ & $43(77)$ & 0.869 \\
\hline \multicolumn{4}{|l|}{ Coronary risk factors } \\
\hline Hypertension & $38(86)$ & $46(82)$ & 0.707 \\
\hline Dyslipidaemia & $35(80)$ & $44(79)$ & 0.955 \\
\hline Diabetes mellitus & $19(43)$ & $21(38)$ & 0.614 \\
\hline Current smoker & $24(55)$ & $25(45)$ & 0.369 \\
\hline Haemodialysis & $1(2)$ & $2(4)$ & 0.999 \\
\hline Prior MI & $12(27)$ & $12(21)$ & 0.529 \\
\hline Prior $\mathrm{PCl}$ & $13(30)$ & $21(38)$ & 0.369 \\
\hline \multicolumn{4}{|l|}{ Clinical presentation at stenting } \\
\hline Stable coronary artery disease & $34(77)$ & $46(82)$ & 0.546 \\
\hline Unstable angina & $6(14)$ & $9(16)$ & 0.735 \\
\hline Acute myocardial infarction & $4(9)$ & $1(2)$ & 0.166 \\
\hline \multicolumn{4}{|l|}{ Medications } \\
\hline Aspirin & $44(100)$ & $56(100)$ & 1.000 \\
\hline Thienopyridines & $44(100)$ & $56(100)$ & 1.000 \\
\hline Statins & $39(89)$ & $45(80)$ & 0.347 \\
\hline Insulin & $5(11)$ & $5(9)$ & 0.687 \\
\hline ACE-I/ARB & $34(77)$ & 33 (59) & 0.053 \\
\hline \multicolumn{4}{|c|}{$\begin{array}{l}\text { Values are given as n (\%) or mean and standard deviation. } \\
\text { ACE-I: angiotensin-converting enzyme inhibitor; ARB: angiotensin receptor } \\
\text { blockers; EES: everolimus-eluting stent; MI: myocardial infarction; } \\
\text { PCI: percutaneous coronary intervention; SES: sirolimus-eluting stent }\end{array}$} \\
\hline
\end{tabular}


Table 2. Angiographic findings and procedural characteristics.

\begin{tabular}{|c|c|c|c|}
\hline & EES & SES & $p$-value \\
\hline No. of DES-treated lesions & 48 & 62 & \\
\hline \multicolumn{4}{|l|}{ Before index procedure } \\
\hline Target imaging vessels & & & 0.852 \\
\hline LAD & $21(44)$ & $29(47)$ & \\
\hline LCX & $8(17)$ & $8(13)$ & \\
\hline RCA & $19(39)$ & $25(40)$ & \\
\hline Reference lumen diameter, mm & $2.52 \pm 0.49$ & $2.63 \pm 0.56$ & 0.339 \\
\hline Minimum lumen diameter, mm & $0.77 \pm 0.49$ & $0.83 \pm 0.37$ & 0.536 \\
\hline Percent diameter stenosis, \% & $71 \pm 17$ & $69 \pm 13$ & 0.478 \\
\hline Chronic total occlusion & $2(4)$ & $1(2)$ & 0.579 \\
\hline In-stent restenosis & $3(6)$ & $3(5)$ & 0.999 \\
\hline Bifurcation & $12(25)$ & $15(24)$ & 0.922 \\
\hline Moderate or heavy calcification & $4(8)$ & $11(18)$ & 0.174 \\
\hline \multicolumn{4}{|l|}{ Procedural characteristics } \\
\hline No. of stents/lesion & & & 0.717 \\
\hline 1 & $40(83)$ & $50(81)$ & \\
\hline$>2$ & $8(17)$ & $12(19)$ & \\
\hline Stent diameter, $\mathrm{mm}$ & $3.1 \pm 0.4$ & $3.1 \pm 0.4$ & 0.936 \\
\hline Total stent length/lesion, mm & $25 \pm 12$ & $27 \pm 13$ & 0.404 \\
\hline Direct stenting & $19(39)$ & $15(24)$ & 0.083 \\
\hline Post-dilatation & $29(60)$ & $47(76)$ & 0.083 \\
\hline Kissing balloon dilatation & $5(10)$ & $1(2)$ & 0.084 \\
\hline Maximum inflation pressure, atm & $16 \pm 3$ & $17 \pm 4$ & 0.073 \\
\hline \multicolumn{4}{|l|}{ After index procedure } \\
\hline Minimum lumen diameter, mm & $2.60 \pm 0.52$ & $2.59 \pm 0.42$ & 0.964 \\
\hline Percent diameter stenosis, \% & $9 \pm 7$ & $10 \pm 6$ & 0.549 \\
\hline Acute gain, mm & $1.83 \pm 0.56$ & $1.77 \pm 0.41$ & 0.555 \\
\hline \multicolumn{4}{|l|}{ Follow-up } \\
\hline Minimum lumen diameter, mm & $2.44 \pm 0.55$ & $2.38 \pm 0.55$ & 0.585 \\
\hline Percent diameter stenosis, \% & $14 \pm 14$ & $17 \pm 14$ & 0.325 \\
\hline Late lumen loss, mm & $0.14 \pm 0.47$ & $0.22 \pm 0.35$ & 0.399 \\
\hline In-stent binary restenosis & $3(6)$ & $3(5)$ & 0.999 \\
\hline Target lesion revascularisation & $3(6)$ & $3(5)$ & 0.687 \\
\hline \multicolumn{4}{|c|}{$\begin{array}{l}\text { Values are given as \% or mean and standard deviation. DES: drug- } \\
\text { eluting stent; EES: everolimus-eluting stent; LAD: left anterior } \\
\text { descending coronary artery; LCX: left circumflex coronary artery; } \\
\text { RCA: right coronary artery; SES: sirolimus-eluting stent }\end{array}$} \\
\hline
\end{tabular}

in EES and 5\% in SES were excluded from the analysis due to out-of-the-screen, poor image quality caused by residual blood, or artefacts $(\mathrm{p}=0.482)$. The results of the OCT analysis are summarised in Table 3. In the stent strut level analysis, the frequency of covered struts in EES and SES was $92.2 \%$ and $85.8 \%$, respectively $(\mathrm{p}<0.001)$. Mean neointimal thickness in EES and SES was $134 \pm 108 \mu \mathrm{m}$ and $123 \pm 111 \mu \mathrm{m}$, respectively $(\mathrm{p}<0.001)$ (Figure 1).

In the DES-treated lesion level analysis, the percentage of uncovered struts ( $8 \pm 15 \%$ vs. $14 \pm 19 \%, \mathrm{p}=0.031)$, the percentage of frames with $>30 \%$ uncovered struts ( $6 \pm 14 \%$ vs. $18 \pm 29 \%$, $p=0.009)$, and the
Table 3. OCT findings at nine-month follow-up.

\begin{tabular}{|c|c|c|c|}
\hline & EES & SES & $p$-value \\
\hline \multicolumn{4}{|l|}{ Stent strut level analysis } \\
\hline No. of struts & 10,712 & 11,860 & \\
\hline Well-apposed \& covered struts & $9,847(91.9)$ & $10,059(84.8)$ & $<0.001$ \\
\hline Well-apposed \& uncovered struts & $762(7.1)$ & $1,547(13.0)$ & $<0.001$ \\
\hline Incompletely apposed \& covered struts & $11(0.1)$ & $83(0.7)$ & $<0.001$ \\
\hline Incompletely apposed \& uncovered struts & $36(0.3)$ & $130(1.1)$ & $<0.001$ \\
\hline Side branch orifice \& covered struts & $23(0.2)$ & $30(0.3)$ & $<0.001$ \\
\hline Side branch orifice \& uncovered struts & $33(0.3)$ & $11(0.1)$ & $<0.00$ \\
\hline
\end{tabular}

\section{DES-treated lesion level analysis}

\begin{tabular}{|l|c|c|c|}
\hline No. of DES-treated lesions & 48 & 62 & \\
\hline Stent struts & $223 \pm 132$ & $191 \pm 98$ & 0.149 \\
\hline Percentage of uncovered struts, \% & $8 \pm 15$ & $14 \pm 19$ & 0.031 \\
\hline Lesions with uncovered struts & 30 (63) & $51(82)$ & 0.020 \\
\hline $\begin{array}{l}\text { Percentage of frames with }>30 \% \\
\text { uncovered struts, \% }\end{array}$ & $6 \pm 14$ & $18 \pm 29$ & 0.009 \\
\hline $\begin{array}{l}\text { Maximum length of segments with } \\
\text { uncovered struts, mm }\end{array}$ & $1.8 \pm 2.9$ & $4.4 \pm 5.5$ & 0.003 \\
\hline $\begin{array}{l}\text { Percentage of incompletely apposed } \\
\text { struts, \% }\end{array}$ & $1 \pm 1$ & $2 \pm 4$ & 0.017 \\
\hline Lesions with ISA & $8(17)$ & $29(47)$ & $<0.001$ \\
\hline $\begin{array}{l}\text { Maximum length of segments with } \\
\text { ISA, mm }\end{array}$ & $0.2 \pm 0.5$ & $1.2 \pm 2.1$ & 0.001 \\
\hline Intra-stent thrombus & $1(2)$ & $5(8)$ & 0.229 \\
\hline Neointimal tissue characteristics & & & 0.039 \\
\hline \multicolumn{1}{|l}{ Homogenous } & $40(83)$ & $40(65)$ & \\
\hline Heterogeneous & $2(4)$ & $12(19)$ & \\
\hline Layered & $6(13)$ & $10(16)$ & \\
\hline
\end{tabular}

\section{Morphometric analysis}

\begin{tabular}{|l|c|c|c|}
\hline Minimum lumen area, $\mathrm{mm}^{2}$ & $5.58 \pm 2.38$ & $5.37 \pm 2.40$ & 0.652 \\
\hline Minimum stent area, $\mathrm{mm}^{2}$ & $6.87 \pm 2.29$ & $6.62 \pm 2.21$ & 0.552 \\
\hline Maximum neointima area, $\mathrm{mm}^{2}$ & $2.37 \pm 1.55$ & $2.13 \pm 1.23$ & 0.366 \\
\hline Maximum ISA area, $\mathrm{mm}^{2}$ & $0.17 \pm 0.48$ & $0.43 \pm 0.78$ & 0.041 \\
\hline Lumen volume, $\mathrm{mm}^{3}$ & $166.99 \pm 89.58$ & $155.61 \pm 80.36$ & 0.440 \\
\hline Stent volume, $\mathrm{mm}^{3}$ & $200.64 \pm 114.97$ & $180.63 \pm 96.35$ & 0.323 \\
\hline Neointima volume, $\mathrm{mm}^{3}$ & $34.01 \pm 30.05$ & $26.61 \pm 23.06$ & 0.146 \\
\hline ISA volume, $\mathrm{mm}^{3}$ & $0.36 \pm 1.42$ & $1.58 \pm 3.62$ & 0.029 \\
\hline Percent neointima volume obstruction, \% & $16 \pm 7$ & $15 \pm 8$ & 0.277 \\
\hline $\begin{array}{l}\text { Values are given as \% or mean and standard deviation. DES: drug-eluting stent; } \\
\text { EES: everolimus-eluting stent; ISA: incomplete stent apposition; 0CT: optical coherence } \\
\text { tomography; SES: sirolimus-eluting stent }\end{array}$ \\
\hline
\end{tabular}

frequency of DES-treated lesions with uncovered struts (30 [63\%] vs. 51 [82\%], $\mathrm{p}=0.020$ ) were significantly lower in EES compared with SES. The maximum length of segment with uncovered struts was significantly shorter in EES compared with SES $(1.8 \pm 2.9 \mathrm{~mm}$ vs. $4.4 \pm 5.5 \mathrm{~mm}, \mathrm{p}=0.003)$. The percentage of incompletely apposed struts $(1 \pm 1 \%$ vs. $2 \pm 4 \%, \mathrm{p}=0.017)$ and the frequency of DES-treated lesions with ISA (8 [17\%] vs. 29 [47\%], p<0.001) were significantly lower in EES compared with SES. The maximum length of 


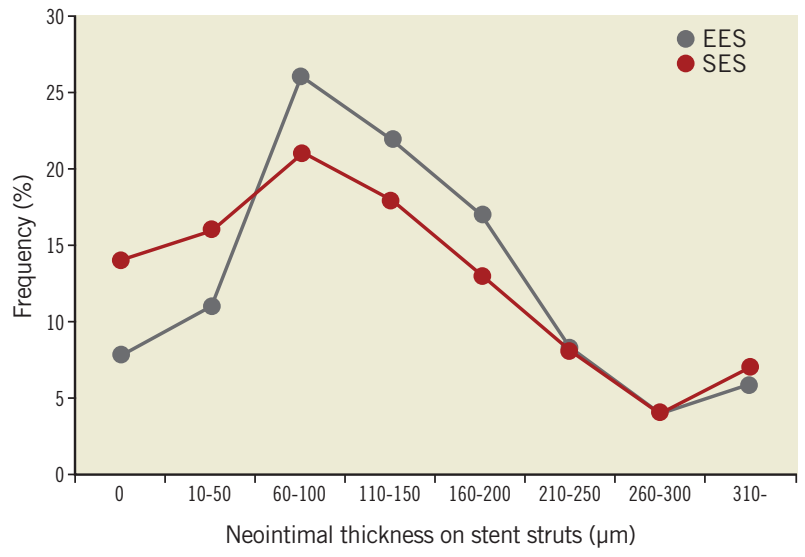

Figure 1. The distributions of neointimal thickness at intervals of $50 \mu \mathrm{m}$. In EES, the percentages of stent struts with a neointimal thickness of 0, 10-50, 60-100, 110-150, 160-200, 210-250, 260-300, and $\geq 310 \mu \mathrm{m}$ were $8 \%, 11 \%, 26 \%, 22 \%, 17 \%, 8 \%, 4 \%$, and $6 \%$, respectively. Those for SES were 14\%, 16\%, 21\%, 18\%, 13\%, 8\%, $4 \%$, and $7 \%$, respectively. The distribution of neointimal thickness was significantly different between EES and SES $(p<0.001)$.

segment with ISA was significantly shorter in EES compared with SES $(0.2 \pm 0.5 \mathrm{~mm}$ vs. $1.2 \pm 2.1 \mathrm{~mm}, \mathrm{p}=0.001)$. Although the volumes of lumen, stent, and neointima were similar between EES and SES, maximum ISA area $\left(0.17 \pm 0.48 \mathrm{~mm}^{2}\right.$ vs. $\left.0.43 \pm 0.78 \mathrm{~mm}^{2}, \mathrm{p}=0.041\right)$ and ISA volume $\left(0.36 \pm 1.42 \mathrm{~mm}^{3}\right.$ vs. $\left.1.58 \pm 3.62 \mathrm{~mm}^{3}, \mathrm{p}=0.029\right)$ were significantly smaller in EES compared with SES. The frequency of intra-stent thrombus was comparable between EES and SES (one [2\%] vs. five [8\%], $\mathrm{p}=0.229$ ). Representative OCT images of EES and SES are shown in Figure 2 and Figure 3, respectively.

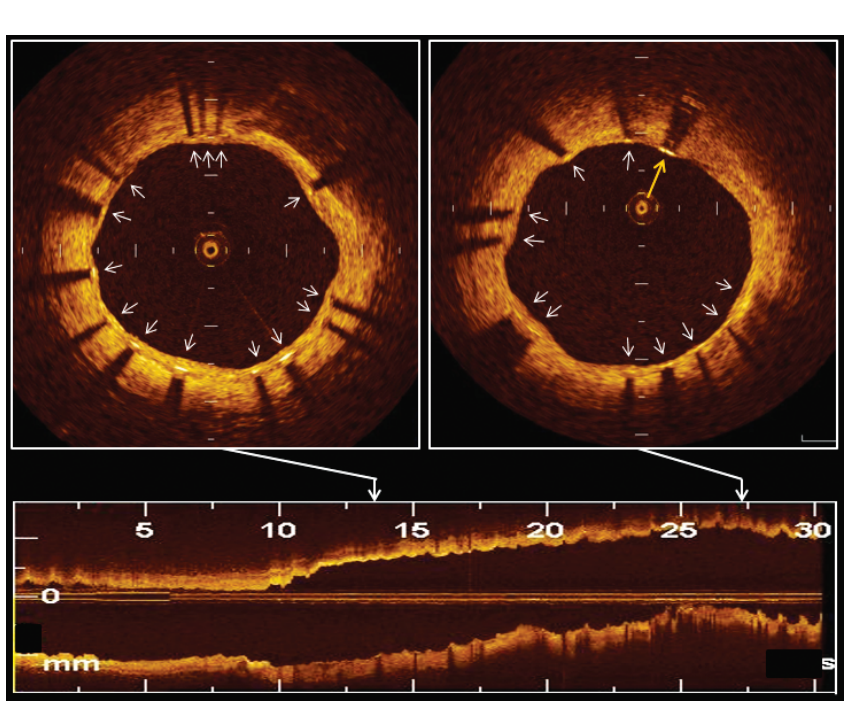

Figure 2. Representative OCT images of EES at 9-month follow-up. OCT visualised well-apposed struts with neointimal coverage (white arrows) and a well-apposed strut without neointimal coverage (yellow arrow).

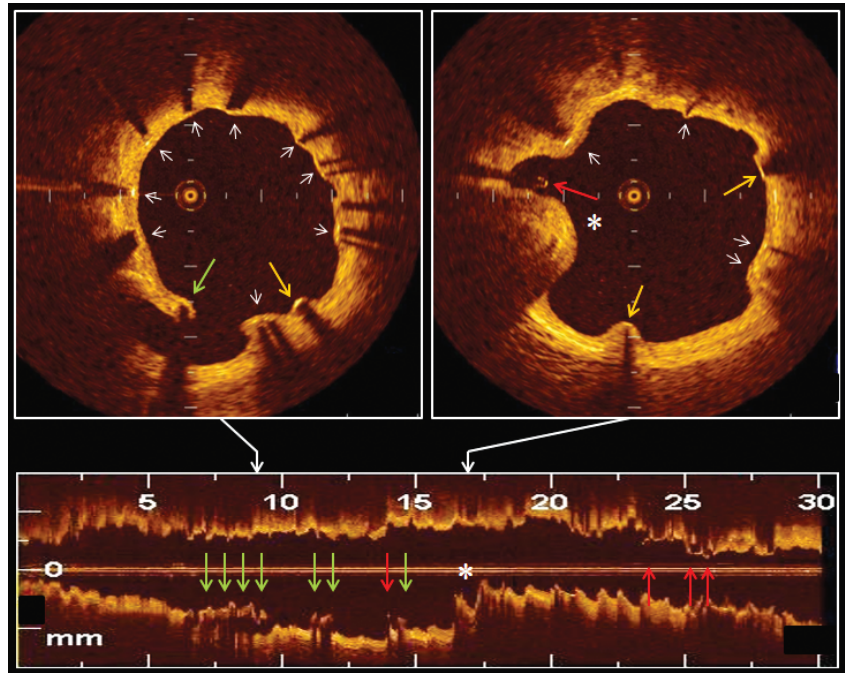

Figure 3. Representative OCT images of SES at 9-month follow-up. OCT visualised well-apposed struts with neointimal coverage (white arrows), well-apposed struts without neointimal coverage (yellow arrows), incompletely apposed struts with neointimal coverage (green arrows), incompletely apposed struts without neointimal coverage (red arrows), and an intra-stent thrombus (*).

\section{Discussion}

The main findings of the present OCT study at nine months after DES implantation are the following: 1) both EES and SES provided excellent suppression of neointimal growth; and 2) stent struts not covered by neointima, incompletely apposed struts, and intra-stent thrombi were significantly less frequently observed in EES compared with SES. Our results suggest that the vascular healing response is different between the first-generation SES and the second-generation EES.

\section{VASCULAR RESPONSE AFTER DES}

SES was the most widely used and most extensively studied firstgeneration DES. Clinical outcomes after SES implantation should be regarded as the benchmark for the current and future generations of DES. Several randomised trials comparing EES with SES, in general, suggested similar efficacy and safety outcomes ${ }^{10-12}$. The RESET also demonstrated that there was no significant difference between the two types of limus-eluting stent in terms of target lesion revascularisation at one year ${ }^{3}$. However, there is no well-powered trial for comparing the incidence of stent thrombosis, which is an infrequent but serious complication after DES implantation. Human autopsy studies have shown that delayed arterial healing is a major underlying substrate of late DES thrombosis ${ }^{1,2}$. Recently, OCT has been introduced as a high-resolution imaging technique. OCT enables researchers to evaluate the vascular healing response after DES, including neointimal coverage of stent and ISA, in living patients ${ }^{13}$. Therefore, this imaging technique might have a potential to provide valuable information for predicting late DES thrombosis. 


\section{NEOINTIMAL COVERAGE}

Lack of neointimal coverage over stent struts is an important pathologic substrate underlying late DES thrombosis. Pathological studies from patients who died of late DES thrombosis have suggested a marked increase in risk for stent thrombosis as the number of uncovered struts increased ${ }^{1,2}$. Finn et al demonstrated that a ratio of uncovered to total stent struts per section $>30 \%$ was highly associated with late DES thrombosis (odds ratio $=9.0 ; 95 \%$ confidence interval $=3.5-22)^{1}$. In the present OCT study at nine months after DES implantation, the percentage of uncovered struts per lesion, the percentage of cross-sections with $>30 \%$ uncovered struts per lesion, and the frequency of DES-treated lesions with uncovered struts were significantly lower in EES compared with SES. The second-generation EES might suppress neointimal growth without sacrificing safety. In addition, heterogeneous neointimal tissue was less frequently observed in EES than in SES. Further investigations are needed to evaluate the clinical implication of the difference in neointimal tissue characteristics.

\section{ISA}

ISA has also been regarded as an important predictor of late and very late DES thrombosis. Although the impact of acute and persistent ISA remains controversial, late-acquired ISA and extensive vessel remodelling are considered to be markers of underlying vascular toxicity and inflammation, likely causes of late and very late DES thrombosis ${ }^{1,2}$. Using angiography, Imai et al demonstrated that peri-stent contrast staining, which suggested the presence of ISA, was associated with very late stent thrombosis ${ }^{14}$. A previous intravascular ultrasound study by Cook et al revealed the association between ISA and very late stent thrombosis after DES ${ }^{15}$. More recently, an OCT study by Guagliumi et al disclosed that patients with very late DES thrombosis had a higher percentage of incompletely apposed struts, larger area of ISA, and greater length of segments with ISA in comparison with control subjects ${ }^{16}$. In the present study, incompletely apposed struts were significantly less frequently observed in EES compared with SES. Furthermore, the maximum length of segments with ISA was significantly shorter in EES, and maximum ISA area and ISA volume were significantly smaller in EES compared with SES. In relation to ISA, EES at nine months after implantation might therefore have a lower potential for thrombogenicity in comparison with SES.

\section{STENT THROMBOSIS}

Recent angioscopy and OCT studies revealed that thrombus is commonly detected in lesions treated with $\mathrm{SES}^{8,16}$. Although thrombosis with complete stent obstruction requires specific factors such as blood flow stasis or increased coagulability, in addition to the thrombogenicity of uncovered struts and ISA, the presence of intra-stent thrombus may contribute to future catastrophic events. The second-generation EES is coated with a fluorinated copolymer that confers a certain degree of thromboresistance and haemocompatibility ${ }^{17}$. A recent prospective cohort study comparing EES with other DES demonstrated that EES use was associated with a marked reduction of stent thrombosis, particularly very late stent thrombosis ${ }^{18}$. In the present study, the frequency of intra-stent thrombus was comparable between EES and SES. The direct relationship between OCT-detected intra-stent thrombus and clinical stent thrombosis should be assessed in future studies.

\section{Limitations}

There are some limitations in the present study. First, selection bias might have affected the results because the patients enrolled in the present OCT substudy were not randomly selected from the RESET, and the inclusion of the patients was flexible and totally dependent on the investigators' decision. Second, because the patients were free of major adverse events after DES implantation until the OCT follow-up, the DES-treated lesions of the present study may not represent those seen in realworld practice. Third, OCT data before and immediately after stent implantation were not available. Therefore, it was unclear whether the ISA and intra-stent thrombus were persistent or newly acquired. Fourth, the present study was not powered or designed to assess the relationship between the suboptimal stent results as determined by OCT and future development of stent thrombosis. Further studies are required to investigate the clinical implications of the OCT findings at nine months after DES implantation. Fifth, current OCT systems cannot detect $<10 \mu \mathrm{m}$ tissue coverage on the stent struts. Endothelial cell dimensions are below the resolution of even OCT, and it is possible that some struts appearing bare were covered by endothelium, and thus misclassified. Sixth, OCT cannot differentiate very small amounts of fibrin deposition or inflammatory cellular response from underlying neointimal hyperplasia. Future developments in OCT technology are necessary to allow tissue characterisation. Seventh, the present study did not use a recently developed frequency-domain OCT, but used a conventional time-domain OCT. However, it is unlikely that assessment of stent coverage and neointimal thickness would be affected. Eighth, SES has already left the coronary DES arena. Therefore, the current trial result may not provide guidance regarding selection of coronary DES in clinical practice. Finally, the major limitation of the present study is the over-simplistic statistical analysis of such a complex OCT data set. The applied analyses are inappropriate for clustered data, and the results can only be understood as an approximation.

\section{Conclusions}

In the present OCT sub-analysis from the RESET, both EES and SES showed excellent suppression of neointimal growth at nine months after stent implantation. EES had a significantly lower frequency of incomplete neointimal coverage and ISA than SES. Compared with the first-generation SES, the second-generation EES might have more favourable vascular responses after stent implantation. 


\section{Impact on daily practice}

Delayed arterial healing characterised by incomplete re-endothelialisation is an important underlying substrate for very late drug-eluting stent (DES) thrombosis. Neointimal growth is an excellent surrogate indicator of re-endothelialisation. Therefore, detection of neointima over the stent struts gives valuable information for predicting stent thrombosis. The present optical coherence tomography (OCT) study at nine months after stent implantation demonstrated similar suppression of neointimal growth, fewer struts not covered by neointima and better stent apposition to the vessel wall in the second-generation everolimus-eluting stent (EES) compared with the first-generation sirolimus-eluting stent (SES). Our data confirm the safety and efficacy profile of EES, complementing the previously reported evidence from large-scale clinical trials.

\section{Acknowledgements}

We appreciate the effort of the members of the cardiac catheterisation laboratory and clinical research coordinators in the participating centres.

\section{Funding}

Abbott Vascular.

\section{Conflict of interest statement}

T. Kimura and K. Kozuma were advisory board members of Abbott Vascular. The other authors have no conflicts of interest to declare.

\section{References}

1. Finn AV, Joner M, Nakazawa G, Kolodgie F, Newell J, John MC, Gold HK, Virmani R. Pathological correlates of late drug-eluting stent thrombosis: strut coverage as a marker of endothelialization. Circulation. 2007;115:2435-41.

2. Nakazawa G, Finn AV, Joner M, Ladich E, Kutys R, Mont EK, Gold HK, Burke AP, Kolodgie FD, Virmani R. Delayed arterial healing and increased late stent thrombosis at culprit sites after drug-eluting stent placement for acute myocardial infarction patients: an autopsy study. Circulation. 2008;118:1138-45.

3. Kimura T, Morimoto T, Natsuaki M, Shiomi H, Igarashi K, Kadota K, Tanabe K, Morino Y, Akasaka T, Takatsu Y, Nishikawa H, Yamamoto Y, Nakagawa Y, Hayashi Y, Iwabuchi M, Umeda H, Kawai K, Okada H, Kimura K, Simonton CA, Kozuma K; RESET Investigators. Comparison of everolimus-eluting and sirolimuseluting coronary stents: 1-year outcomes from the Randomized Evaluation of Sirolimus-eluting Versus Everolimus-eluting stent Trial (RESET). Circulation. 2012;126:1225-36.

4. Matsumoto D, Shite J, Shinke T, Otake H, Tanino Y, Ogasawara D, Sawada T, Paredes OL, Hirata K, Yokoyama M. Neointimal coverage of sirolimus eluting stents at 6-month followup: evaluated by optical coherence tomography. Eur Heart J. 2007;28:961-7.
5. Guagliumi G, Sirbu V, Musumeci G, Gerber R, BiondiZoccai G, Ikejima H, Ladich E, Lortkipanidze N, Matiashvili A, Valsecchi O, Virmani R, Stone GW. Examination of the in vivo mechanisms of late drug-eluting stent thrombosis: findings from optical coherence tomography and intravascular ultrasound imaging. JACC Cardiovasc Interv. 2012;5:12-20.

6. Kataiwa H, Tanaka A, Kitabata H, Imanishi T, Akasaka T. Safety and usefulness of non-occlusion image acquisition technique for optical coherence tomography. Circ J. 2008;72:1536-7.

7. Kume T, Akasaka T, Kawamoto T, Ogasawara Y, Watanabe N, Toyota E, Neishi Y, Sukmawan R, Sadahira Y, Yoshida K. Assessment of coronary arterial thrombus by optical coherence tomography. Am J Cardiol. 2006;97:1713-7.

8. Miyoshi N, Shite J, Shinke T, Otake H, Tanino Y, Ogasawara D, Sawada T, Kawamori H, Kato H, Yoshino N, Kozuki A, Hirata K. Comparison by optical coherence tomography of paclitaxel-eluting stents with sirolimus-eluting stents implanted in one coronary artery in one procedure. - 6-month follow-up -. Circ J. 2010;74:903-8.

9. Gonzalo N, Serruys PW, Okamura T, van Beusekom HM, Garcia-Garcia HM, van Soest G, van der Giessen W, Regar E. Optical coherence tomography patterns of stent restenosis. Am Heart J. 2009;158:284-93.

10. Park KW, Chae IH, Lim DS, Han KR, Yang HM, Lee HY, Kang HJ, Koo BK, Ahn T, Yoon JH, Jeong MH, Hong TJ, Chung WY, Jo SH, Choi YJ, Hur SH, Kwon HM, Chun DW, Kim BO, Park SH, Lee NH, Jeon HK, Gwon HC, Jang YS, Kim HS. Everolimuseluting versus sirolimus-eluting stents in patients undergoing percutaneous coronary interventions: the EXCELLENT (Efficacy of Xience/Promus Versus Cypher to Reduce Late Loss After Stenting) randomized trial. J Am Coll Cardiol. 2011;58:1844-54.

11. Byrne RA, Kastrati A, Massberg S, Wieczorek A, Laugwitz KL, Hadamitzky M, Schulz S, Pache J, Fusaro M, Hausleiter J, Schömig A, Mehilli M; ISAR-TEST 4 Investigators. Biodegradable polymer versus permanent polymer drug-eluting stents and everolimus- versus sirolimus-eluting stents in patients with coronary artery disease: 3-year outcomes from a randomized clinical trial. J Am Coll Cardiol. 2011;58:1325-31.

12. Jensen LO, Thayssen $\mathrm{P}$, Hansen HS, Christiansen EH, Tilsted HH, Krusell LR, Villadsen AB, Junker A, Hansen KN, Kaltoft A, Maeng M, Pedersen KE, Kristensen SD, Bøtker HE, Ravkilde J, Sanchez R, Aarøe J, Madsen M, Sørensen HT, Thuesen L, Lassen JF; Scandinavian Organization for Randomized Trials With Clinical Outcome IV (SORT OUT IV) Investigators. Randomized comparison of everolimus-eluting and sirolimuseluting stents in patients treated with percutaneous coronary intervention: the Scandinavian Organization for Randomized Trials with Clinical Outcome IV (SORT OUT IV). Circulation. 2012; 125:1246-55.

13. Kubo T, Imanishi T, Kitabata H, Kuroi A, Ueno S, Yamano T, Tanimoto T, Matsuo Y, Masho T, Takarada S, Tanaka A, Nakamura N, Mizukoshi M, Tomobuchi Y, Akasaka T. Comparison of vascular response after sirolimus-eluting stent implantation between patients with unstable and stable angina pectoris: a serial 
optical coherence tomography study. JACC Cardiovasc Imaging. 2008;1:475-84.

14. Imai M, Kadota K, Goto T, Fujii S, Yamamoto H, Fuku Y, Hosogi S, Hirono A, Tanaka H, Tada T, Morimoto T, Shiomi H, Kozuma K, Inoue K, Suzuki N, Kimura T, Mitsudo K. Incidence, risk factors, and clinical sequelae of angiographic peri-stent contrast staining after sirolimus-eluting stent implantation. Circulation. 2011;123:2382-91.

15. Cook S, Wenaweser P, Togni M, Billinger M, Morger C, Seiler C, Vogel R, Hess O, Meier B, Windecker S. Incomplete stent apposition and very late stent thrombosis after drug-eluting stent implantation. Circulation. 2007;115:2426-34.

16. Kotani J, Awata M, Nanto S, Uematsu M, Oshima F, Minamiguchi H, Mintz GS, Nagata S. Incomplete neointimal coverage of sirolimus-eluting stents: angioscopic findings. $J \mathrm{Am}$ Coll Cardiol. 2006;47:2108-11.

17. Kolandaivelu K, Swaminathan R, Gibson WJ, Kolachalama VB, Nguyen-Ehrenreich KL, Giddings VL, Coleman L, Wong GK, Edelman ER. Stent thrombogenicity early in high-risk interventional settings is driven by stent design and deployment and protected by polymer-drug coatings. Circulation. 2011;123:1400-9.

18. Räber L, Magro M, Stefanini GG, Kalesan B, van Domburg RT, Onuma Y, Wenaweser P, Daemen J, Meier B, Jüni P, Serruys PW, Windecker S. Very late stent thrombosis of a newer generation everolimus-eluting stent compared with early generation drug-eluting stents: a prospective cohort study. Circulation. 2012;125:1110-21. 